\title{
6. Moderators of unemployment and wage scarring during the transition to young adulthood: evidence from Norway
}

\section{Dawit Shawel Abebe and Christer Hyggen}

\section{INTRODUCTION}

Entering the labour force is one of the most significant life events for young adults and is a central element of the transition to adulthood. Employment ideally provides - in addition to material security - social integration, identity and status. The experience of unemployment or employment instability during young adulthood may have long-term negative effects on labour market integration - so called scarring effects - as well as on subjective and objective well-being (Bell and Blanchflower, 2011; Gregg and Tominey, 2005; Luijkx and Wolbers, 2009; Nilsen and Reiso, 2011; Nordström Skans, 2004; Schmillen and Umkehrer, 2013).

The effect of scarring is well documented in the research literature, but less is known about the mechanisms behind such effects amongst young workers. The state of scarring on the individual has been explained by either exposure to early unemployment or observed and/ or unobserved individual and family characteristics affecting the job offers or employment possibilities available to young people over time. Individual and family characteristics related to multiple domains may reveal direct and indirect pathways that suggest causal mechanisms of labour market outcomes for young people (Caspi et al., 1998). The direct pathway proposes that personal characteristics may directly affect job-search behaviour and job performance, which in turn influence opportunities for job offers and employment stability in later life. The indirect pathway proposes that individual and family characteristics may negatively affect other life events, such as education - highschool completion and college attendance - that are vital for securing employment (Caspi et al., 1998). 
The present longitudinal study is aimed at investigating how exposure to early unemployment episodes and individual and family characteristics during adolescence causally moderate long-term labour market outcomes in Norway. Insight into moderators of labour market outcomes is crucial for understanding the causal mechanisms underlying scarring effects. Such knowledge may also be important for policy and programmes aimed at reducing unemployment and improving the ability of young people to cope with and exit unemployment, as well as reducing socioeconomic inequality in the general population. Using a rich and unique data set, including data on personal characteristics (such as self-esteem, conduct problems and impulsivity), family characteristics (such as parental bonding style) and labour market outcomes over time, this chapter contributes to the literature by identifying causal moderators of unemployment scarring.

In Section 2 we review relevant literature addressing moderators of unemployment scarring. In Section 3 we describe the data used and the methods applied in our analyses. Section 4 of the chapter contains the central analyses. In the final section we discuss the analyses and present conclusions.

\section{MODERATORS OF UNEMPLOYMENT SCARRING}

Given its potential effects on educational and occupational choice, and family patterns and preferences, gender has been commonly investigated as an individual factor that moderates scarring effects. Although unemployment and wage scarring are found significantly in both females and males (Nilsen and Reiso, 2011), distinct gendered patterns of unemployment scarring have been reported in previous research. Unemployment scarring accumulated with lengthy and repeated unemployment is not as distinct amongst women as amongst men. Women are also found to be subject to weaker effects of unemployment scarring related to the loss of occupation-specific knowledge and to the more temporary character of women's employment contracts (Mooi-Reci and Ganzeboom, 2015).

The importance of education for employment and career opportunities is also well documented, but there is less evidence regarding the possible moderating effect of education on scarring. Studies have, however, documented more severe scarring effects of unemployment in terms of recurring or persistent unemployment and lower wages for young people with lower education (Grasdal, 2001) and general skills (Hämäläinen, 2003). Possible moderating effects of education on scarring could be given demand-side or supply-side explanations (Helbling et al., 2016). Higher levels of education may signal higher productivity to a potential employer 
(Spence, 1973), despite experience of unemployment, or may be subject to a smaller degree of skills depreciation (Pissarides, 1992) or loss of human capital over time (Becker, 1964; Pissarides, 1992).

So far, few studies have asked how other early individual and family characteristics relate to the development of labour market outcomes during the transition to adulthood. One that has is the Dunedin Multidisciplinary Health and Development Study, which revealed the following predictors for youth unemployment (at age 21): (1) human capital - poor academic qualifications and skills and limited parental resources; (2) social capital growing up in a single-parent family, family conflict and lack of school attachment; and (3) personal capital - antisocial behaviours (Caspi et al., 1998). Moreover, findings from a UK longitudinal study supported the indirect pathway by indicating that antisocial boys had lower earnings during adulthood and that such poor employment outcomes could be mediated through poor educational attainment and higher rates of criminal conviction in early adulthood (Healey et al., 2004).

Other studies found that self-control (Daly et al., 2015), self-esteem (Trzesniewski et al., 2006), social competence (Heckman et al., 2006; Masten et al., 2010) and substance-use behaviours (Henkel, 2011) in childhood may influence labour force entry and job retention during adulthood, particularly in times of economic uncertainty (Daly et al., 2015). For instance, adolescents with problematic substance-use behaviours may have limited ability to attain a favourable socioeconomic status (SES), which supports the social selection hypothesis (Henkel, 2011). Furthermore, childhood health, parental SES and family functioning have been shown to impact on future educational and labour market outcomes (Currie, 2009; Elman and O'Rand, 2004; Haas et al., 2011).

However, it has remained unclear how these early individual and family characteristics are causally associated with or moderate long-term labour market participation during the transition to adulthood. The present Norwegian longitudinal study is therefore aimed at investigating how both exposure to early unemployment episodes and individual and family characteristics during adolescence causally moderate long-term labour market outcomes (i.e., employment and wage status) in the mid-30s. Specifically, we analyse the following factors as moderators for the development of scarring effects: gender, level of education, parental SES (measured by levels of education) and psychological well-being (measured by mental distress and substance-use behaviours). The rich available data allow us to consider important factors concerning the level of psychosocial problems in the individual when comparing young people who have experienced early job insecurity with those who have not. 


\section{METHODS}

\subsection{Sampling Strategies and Participation Rates}

The research behind this chapter used data from the Young in Norway longitudinal study (YiN). The data set includes survey data collected in four waves: 1992 (T1; ages 12-20 years), 1994 (T2; ages 14-22), 1999 (T3; ages 19-28) and 2005 (T4; ages 25-34). The respondents at $\mathrm{T} 4(\mathrm{~N}=2890)$ were asked for their consent to link the survey data to Norwegian population register data, to which 2606 (90 per cent) agreed. From this set of respondents, in order to select a sample representing unemployed versus employed (active in the labour market), we excluded from our analyses those who at $\mathrm{T} 4$ were students $(\mathrm{N}=249)$ or were in receipt of social or welfare benefits $(\mathrm{N}=234)$ (inactive in the labour market). The sample population $(\mathrm{N})$ for the present study was thus 2123. Figure 6A.1 in the Appendix (this chapter) illustrates the sampling design and the participation rates across time points. Full details about the study design and sampling have been published elsewhere (Strand and Von Soest, 2008).

The population register provides time-series sociodemographic and economic data on all legal residents in Norway. In the current study we included SES variables such as level of education for respondents and their parents, annual net income, unemployment status and welfare benefits (social and rehabilitation benefits). We selected the record of these variables for the 2003-07 period as representing a period when the respondents could have been active in the labour market (ages 23 to $37)$. The labour market outcome variables in our study were unemployment status and annual net income from 2004 to 2007. Unemployment status was coded as $0=$ employed and $1=$ unemployed for at least one period during the last 12 months. Annual net income was measured in 1000 NOK (about 100 euros). Unemployment status in 2003 was regarded as an early unemployment exposure and was used to determine unemployment and wage scarring from 2004 to 2007. The participants' highest level of education was coded as $1=$ college and university and 2 $=$ primary and secondary (i.e., one value for the whole period - from 1995 to 2007).

From the survey we included information on age and gender as well as other independent variables representing early predictors of scarring effects. The independent variables, except for information on impulsivity, were mainly selected from $\mathrm{T} 1$ and $\mathrm{T} 2$. This approach helped in delineating temporal precedence between predictors and labour market outcomes, which was essential for establishing the causal associations between predictors and scarring effects. Details about the psychometric properties of 
the instruments that were used to measure variables in the YiN study have been published elsewhere (Strand and Von Soest, 2008).

Alcohol intoxication was measured by asking participants to indicate how often they had 'drunk so much that you felt clearly intoxicated' during the preceding 12 months, while illicit drug use was assessed by asking about the frequency of illicit drug use over the past 12 months (Barnea et al., 1987; Johnson and Mott, 2001). The response scale ranged from 1 ('never') to 6 ('more than 50 times') for both measures. Dummy variables were constructed: at least 10 times alcohol intoxication and one use of illicit drugs in the last 12 months were regarded as cut-off points to indicate problematic substance-use behaviours.

Mental distress - symptoms of depression and anxiety - was measured with a 12-item short version of the Hopkins Symptom Checklist (SCL) (Derogatis et al., 1974). Using a response scale ranging from 1 (not at all) to 4 (extremely), respondents were asked to restrict their ratings to the preceding week. A mean sum score for all items equal to or above 1.85 has proven to be a valid predictor for mental distress amongst subjects aged 16-24 years using SCL-10 (Strand et al., 2009). We applied this cut-off level to categorize low and high levels of mental distress.

A short version of the Parental Bonding Instrument (PBI) (Parker et al., 1979) was used to assess parental bonding styles. The PBI measures the emotional relationship between participants and their parents by focusing on two dimensions: parental care and parental overprotection. Each dimension consists of five items and the respondents rated each of them on a four-point Likert scale from 1 ('very likely') to 4 ('very unlikely'). High scores on the parental care sub-scale indicate a parent-child relationship based on emotional warmth, closeness and empathy, whereas high scores on the parental overprotection subscale indicate parental obstruction of independent behaviour, as well as parental control and parental intrusion (Parker et al., 1979).

General self-esteem was measured using the Global Self-Worth Subscale from the revised version of the Harter Self-Perception Profile for Adolescents (Harter, 2012; Wichstrøm, 1995). Five items assess how an adolescent respondent views himself/herself, with the response options ranging from 1 ('corresponds very poorly') to 4 ('corresponds very well'). Higher mean scores reflect high self-esteem.

Conduct problems were measured using 15 items that are closely related to criteria for conduct disorder (Pedersen et al., 2001; Pedersen and Wichstrøm, 1995). Using a response scale ranging from 1 ('0 times') to 6 ('more than 50 times'), participants were asked to restrict their responses to the last 12 months. High mean scores indicate serious conduct problems (i.e., delinquent actions and aggression). 
Scholastic competence was measured using the revised version of the Harter Self-Perception Profile for Adolescents (Harter, 2012; Wichstrøm, 1995), which includes two sub-scales (both with five items), with the response options ranging from $1=$ 'corresponds very poorly' to $4=$ 'corresponds very well.' High mean scores indicate a high level of perceived self-concept towards scholastic competence.

Impulsivity was measured by seven items, three of which were designed by Eysenck et al. (1985), two of which were taken from a short version of the General Temperament Survey (Colder and Stice, 1998), and the last two of which were constructed for the purpose of the present study. Mean scores were computed, with high scores indicating a high level of impulsivity (reduced self-control).

\subsection{Statistical Analyses}

We applied propensity score matching (PSM) (Caliendo and Kopeinig, 2008; Rosenbaum and Rubin, 1983) to allow for causal conclusions about whether or not exposure to early unemployment leads to the development of scarring effects (i.e., persistence of unemployment and loss of income during young adulthood). We further tested how the development of scarring effects is moderated by gender, levels of education, parental levels of education, substance-use behaviours and mental distress. Since the data set includes comprehensive individual and family characteristics associated with scarring effects, we also controlled for these characteristics, ensuring comparability between those who had been unemployed early (treated) and those who had not experienced unemployment (untreated, control group). Since this method was initially developed for medical research, the medical concepts of treated and untreated (unemployed and employed in our case) are used here, too. We will also refer to these effects as the average causal effects of early unemployment.

Logit models were applied to estimate propensity scores in STATA (Leuven and Sianesi, 2011). As stated in the background section, matching covariates at $\mathrm{T} 1$ and $\mathrm{T} 2$ were included based on previous research suggesting that individual and family characteristics may have an important role in determining early labour market participation and scarring outcomes. These baseline covariates include age, gender, level of education, parental level of education, parental relationships, substance-use behaviours, mental distress, antisocial behaviour, self-esteem, scholastic competence and impulsivity.

A kernel matching algorithm was applied with caliper matching at 0.01 and 0.001 propensity score and bootstrap standard errors. This matching method enables performance of one-to-many matching by calculating 
the weighted average of the outcome variable for the control group (employed) and then comparing the weighted average with the outcome of the treated group (unemployed). The analyses also imposed common support by dropping observations amongst the group who had experienced unemployment with propensity scores higher than the maximum or less than the minimum propensity scores of the controls. These analytical approaches help in reducing bias and estimating the variance of average treatment effects, and also in evaluating the robustness of the results, particularly comparing the results at 0.01 versus 0.001 propensity score (Caliendo and Kopeinig, 2008; Cochran and Rubin, 1973).

The matching quality was examined using standardized bias and t-test. When a baseline covariate showed a percentage bias above 5 per cent, we repeated the PSM analyses by adding interaction terms and/or excluding this covariate and then reassessed the matching quality. Visual analysis of the density of distribution of the propensity score in the treatment and control groups was conducted to check for any violations of the common support condition.

For all analyses, we specified predictors at $\mathrm{T} 1$ and $\mathrm{T} 2$ as a time invariant in order to simplify model fitting and to avoid a different time-person structure between outcome and predictor variables. A p-value of less than 0.05 was considered statistically significant.

This study has some limitations that require careful consideration when interpreting the findings. First, the study was conducted during a period of good macroeconomic conditions, so that scarring effects might be less pronounced (Tumino, 2015). Second, our study did not separate the effects of scarring based on the entry conditions to the labour market, or years or types of employment. Third, unemployment duration and quality of employment status (e.g., temporary or permanent) were not taken into consideration because of lack of data. Finally, we only followed about 25 per cent of the representative sample at T1. Even though most of the attrition was planned, and attrition analyses showed some significant differences between those who dropped out and those who completed the study (Abebe et al., 2012; Wichstrøm, 2000), the large share who dropped out from the follow-ups could be a source of bias.

\section{RESULTS}

\subsection{Descriptive Summary of the Study Populations}

The mean ages of participants were 15.2 (T1); 16.6 (T2); 21.1 (T3) and 28.6 (T4) years. The sample population included 1174 (55.3 per cent) 
Table 6.1 Predicted probabilities of being unemployed showing how early employment status (2003) affected labour market outcomes from 2004 to 2007

\begin{tabular}{lccccc}
\hline Register data & 2003 & 2004 & 2005 & 2006 & 2007 \\
\hline Unemployed - N (\%) & 262 & 271 & 231 & 158 & 115 \\
& $(12.3)$ & $(12.7)$ & $(10.9)$ & $(7.4)$ & $(5.4)$ \\
Predicted probabilities for & & & & & \\
$\quad$ being unemployed if* & & & & & \\
employed in 2003 & - & 0.07 & 0.08 & 0.10 & 0.11 \\
unemployed in 2003 & - & 0.47 & 0.39 & 0.34 & 0.32 \\
annual income in 1000 & 245.3 & 276.6 & 316.1 & 349.2 & 386.2 \\
$\quad$ NOK - M (sd) & $(156.2)$ & $(141.3)$ & $(185.9)$ & $(192.9)$ & $(249.1)$ \\
Predicted probabilities of & - & -3.28 & -3.20 & -3.46 & -1.93 \\
$\quad$ earning if unemployed & & & & & \\
$\quad$ in 2003 & & & & & \\
\hline
\end{tabular}

Source: Author's interpretation.

females and 949 ( 44.7 per cent) males. About 55 per cent of the sample had completed college or university education and had at least one parent with college or university education. Details about individual and family characteristics of the study participants are presented in Table 6A.1 in the Appendix (this chapter).

Table 6.1 presents descriptive statistics and predicted probabilities of labour market outcomes over time. The proportion of unemployed was 12.3 per cent in 2003 and it declined to 5.4 per cent in 2007 as the participants grew older. The predicted probability of being unemployed in 2004 if one had been unemployed early (2003) was 47 per cent, which declined to 32 per cent in 2007. The predicted probability of being unemployed in 2004 if one had been employed in 2003 was 7 per cent, which increased to 11 per cent in 2007. The results also showed that early unemployed had lower earnings (annual net income) over time as compared to early employed.

\subsection{The Development of Unemployment and Wage Scarring}

Table 6.2 presents descriptive summaries of the pre-treatment characteristics of the treated (unemployed early) and control (employed early) groups. The results show to some extent higher psychosocial problems amongst the previously unemployed than amongst the control group.

The average causal effects on the early unemployed are presented in Table 6.3. The results show that the average effect on unemployment 
Table 6.2 Descriptive summary of pre-treatment characteristics of treated (early unemployed) and control (early employed) groups

\begin{tabular}{lccc}
\hline Variables & $\begin{array}{c}\text { Treated } \\
(\mathrm{N}=260)\end{array}$ & $\begin{array}{c}\text { Control } \\
(\mathrm{N}=1845)\end{array}$ & $\begin{array}{c}\text { P-value from } \\
\text { chi }^{2} / \text { t-test }\end{array}$ \\
\hline Age at T4 - M (sd) & $28.33(1.87)$ & $28.56(1.76)$ & 0.051 \\
Gender - N (\%) & $117(45.00)$ & $823(44.61)$ & 0.905 \\
Male & $143(55.00)$ & $1022(55.39)$ & \\
Female & & & $<0.001$ \\
Level of education - N (\%) & $153(58.85)$ & $788(42.71)$ & \\
Junior/Secondary & $107(41.15)$ & $1057(57.29)$ & \\
College/University & & & 0.060 \\
Parental level of education - N (\%) & $97(37.89)$ & $810(44.12)$ & \\
Junior/Secondary & $159(62.11)$ & $1026(55.88)$ & \\
College/University & & & \\
Parental relationships - M (sd) & $2.10(0.52)$ & $2.03(0.49)$ & 0.037 \\
overprotective & $3.09(0.44)$ & $3.18(0.46)$ & 0.003 \\
caring & $61(23.46)$ & $413(22.46)$ & 0.050 \\
Substance-use behaviour - N (\%) & $1.39(0.31)$ & $1.35(0.34)$ & 0.069 \\
Conduct problems - M (sd) & $67(25.87)$ & $376(20.55)$ & 0.050 \\
High levels of mental distress - N (\%) & $2.83(0.45)$ & $2.92(0.46)$ & 0.008 \\
Scholastic competence - M (sd) & $2.90(0.47)$ & $2.94(0.48)$ & 0.203 \\
Self-esteem - M (sd) & $2.59(0.42)$ & $2.46(0.44)$ & $<0.001$ \\
Impulsivity - M (sd) & \multicolumn{2}{c}{} \\
\hline
\end{tabular}

Notes: $\mathrm{N}=$ number; $\mathrm{M}=$ mean; $\%=$ percentage $; \mathrm{sd}=$ standard deviation; $\mathrm{T}=$ survey time.

Source: Author's interpretation.

Table 6.3 Average treatment effect on treated (early unemployed) group for unemployment and wage scarring over time

\begin{tabular}{llcc}
\hline Matching & Caliper & \multicolumn{2}{c}{ Outcomes $-\mathrm{B}(\mathrm{SE})$} \\
\cline { 3 - 4 } methods & & $\begin{array}{c}\text { Unemployment } \\
\text { scarring }\end{array}$ & $\begin{array}{c}\text { Wage scarring (income in } \\
1000 \mathrm{NOK})\end{array}$ \\
\hline Kernel & 0.01 & $0.085(0.019)^{* * *}$ & $-47.768(19.739)^{*}$ \\
& 0.001 & $0.085(0.023)^{* *}$ & $-47.768(15.779)^{* *}$ \\
Radius & 0.01 & $0.083(0.024)^{* * *}$ & $-49.661(17.806)^{* *}$ \\
& 0.001 & $0.082(0.025)^{* *}$ & $-45.054(23.538)$ \\
\hline
\end{tabular}

Notes: $\quad \mathrm{B}=$ observed regression coefficients; $\mathrm{SE}=$ bootstrap standard errors in parentheses; ${ }^{* * *} \mathrm{p}<0.001,{ }^{* *} \mathrm{p}<0.01,{ }^{*} \mathrm{p}<0.05$.

Source: Author's interpretation. 
scarring was statistically significant and close to 0.08 in all matching methods, using both kernel and radius matching. The average effect on annual income was statistically significant and negative in kernel and radius matching (at 0.01 propensity score), suggesting that there was wage scarring amongst those who were unemployed over time.

\subsection{Moderators of the Effects of Treatment on Unemployment and Wage Scarring}

In Table 6.4 we present analyses repeating the PSM analyses and stratifying by gender, levels of education, parental levels of education, mental distress and substance-use behaviours. We understand unemployment scarring as an increased probability of subsequent unemployment amongst

Table 6.4 Average treatment effect on treated (early unemployed) group for unemployment and wage scarring over time stratified by gender, education, parents' education, mental distress and substance use. Kernel matching with caliper 0.01

\begin{tabular}{lccc}
\hline & Caliper & \multicolumn{2}{c}{ Outcomes $-\mathrm{B}(\mathrm{SE})$} \\
\cline { 3 - 4 } & & $\begin{array}{c}\text { Unemployment } \\
\text { scarring }\end{array}$ & $\begin{array}{c}\text { Wage scarring (income } \\
\text { in } 1000 \mathrm{NOK})\end{array}$ \\
\hline $\begin{array}{l}\text { Females } \\
\text { Males }\end{array}$ & 0.01 & $0.095(0.031)^{* *}$ & $-41.584(9.918)^{* * *}$ \\
$\begin{array}{l}\text { Low level of education } \\
\text { High level of education }\end{array}$ & 0.01 & $0.061(0.028)^{*}$ & $-51.409(47.093)$ \\
$\begin{array}{l}\text { Low level of parental } \\
\quad \text { education }\end{array}$ & 0.01 & $0.111(0.029)^{* * *}$ & $-55.694(17.830)^{* *}$ \\
$\begin{array}{l}\text { High level of parental } \\
\quad \text { education }\end{array}$ & 0.01 & $0.059(0.023)^{*}$ & $-34.0255(26.990)$ \\
$\begin{array}{l}\text { Low level of mental } \\
\text { distress }\end{array}$ & 0.01 & $0.081(0.032)^{*}$ & $-71.072(32.984)^{*}$ \\
$\begin{array}{l}\text { High level of mental } \\
\quad \text { distress }\end{array}$ & 0.01 & $0.089(0.047)$ & $-87.050(60.537)$ \\
$\begin{array}{l}\text { Without problematic } \\
\quad \text { substance use }\end{array}$ & 0.01 & $0.068(0.028)^{*}$ & $-51.963(13.753)^{* * *}$ \\
$\begin{array}{l}\text { With problematic } \\
\quad \text { substance use }\end{array}$ & 0.01 & $0.154(0.060)^{*}$ & $-20.666(46.142)$ \\
\hline
\end{tabular}

Notes: $\quad \mathrm{B}=$ observed regression coefficients with bootstrap standard errors in parentheses; $* * * \mathrm{p}<0.001,{ }^{* *} \mathrm{p}<0.01,{ }^{*} \mathrm{p}<0.05$.

Source: Young in Norway longitudinal study. 
the previously unemployed. Similarly, wage scarring is understood as a reduced average income amongst the previously unemployed compared to those who had not been unemployed. From the analyses presented in Table 6.3 we know that the scarring effect on unemployment is about 8 per cent higher probability of subsequent unemployment and that the wage scarring amounts to about 47000 NOK lower wages.

The analyses in Table 6.4 show how these average scarring effects of being unemployed are moderated by factors characterizing the youth themselves and their socioeconomic backgrounds.

We observe unemployment scarring both amongst females and males, but the scarring effects are higher amongst the females. In addition, our analyses reveal statistically significant wage scarring only amongst women. These findings indicate that early unemployment has more detrimental scarring effects for women than for men both regarding unemployment probability and reduced wages.

The analyses show that unemployment scarring is stronger amongst young people with low levels of education than amongst youth with higher levels of education. Statistically significant signs of wage scarring are only found amongst the group of young people with low levels of education. This means that young people with low levels of education are more affected by early unemployment episodes than their peers with higher levels of education - both as regards unemployment probability and future wages.

Regardless of the parental level of education, the analyses reveal significant effects on unemployment scarring. However, only amongst youth whose parents have low levels of education do we observe wage scarring.

When stratifying by level of self-reported mental distress, we are only able to identify significant effects on unemployment scarring amongst young people with low levels of mental distress.

Finally, we observe unemployment scarring amongst individuals both with and without problematic substance-use behaviours. However, the effects were almost twice as high amongst those with problematic substance-use behaviours as compared to those without.

In all the discussed PSM results the mean percentage bias was less than 5 per cent for most covariates. The t-test showed non-significant statistical differences in covariates for both groups. This result indicates that the matching strategies succeeded in making the distributions of the covariates similar between the early unemployed and the control groups without early unemployment. Detailed results are available on request from the authors. Results showing both kernel and radius matching with caliper at 0.01 and 0.001 can be found in Tables 6A.2 to 6A.6 in the Appendix (this chapter). 


\section{CONCLUSION}

Unemployment leaves scars on young individuals entering the labour market. Our findings reveal that an early unemployment episode is a causal risk factor for unemployment and income inequality during young adulthood. In other words, experience of early unemployment episodes is regarded as a main pathway leading to the development of unemployment and wage scarring. This finding is consistent with previous results (Biewen and Steffes, 2010; Gregg, 2001; Gregg and Tominey, 2005; Nilsen and Reiso, 2011; Raaum and Røed, 2006). Individuals who have experienced brief early periods of unemployment more often remain unemployed and subject to loss of income for extended periods during young adulthood. Our study therefore further substantiates previous evidence that early unemployment leaves young workers with long-term scars (Nilsen and Reiso, 2011).

However, unemployment cuts deeper and leaves more visible scars on some young people than on others. Our findings suggest that gender, levels of education, parental education and psychological well-being all moderate the effects of an early unemployment episode on long-term labour market outcomes. Specifically, females appear to have a greater risk of more significant unemployment and wage scarring than do males. This finding is in contrast to results from previous studies on associations between gender and scarring. For instance, a register study in Norway reported almost similar levels of unemployment scarring for females and males (Nilsen and Reiso, 2011). Another study in the Netherlands indicated stronger effects of unemployment scarring amongst men than amongst women, and also gender variations in mechanisms underlying unemployment scarring: the effects of unemployment scarring are predominately driven by human capital depreciation for women, while amongst men stigma effects play a central role (Mooi-Reci and Ganzeboom, 2015). The more severe scarring effects on young females observed here may be partly due to the gender segregation of the Norwegian labour market in terms of occupations, where the public sector is dominated by female workers and the private sector is dominated by males (Jensberg et al., 2012). Young males have a higher probability of experiencing unemployment because of their orientation towards the less protected private sector.

Levels of education have shown marked effects on unemployment and wage scarring: having a high level of education may buffer the development of unemployment and wage scarring over time. Our finding substantiates previous evidence that level of education moderates scarring effects. Other studies correspondingly documented the importance of education in employment and career opportunities (Grasdal, 2001; Hämäläinen, 2003; Spence, 1973). 
Our findings on the moderating roles of parental level of education and early psychological well-being are to some extent inconsistent. Prior studies have shown that parental SES affects future educational and labour market outcomes amongst young people (Currie, 2009; Elman and O'Rand, 2004; Haas et al., 2011), but the present study does not confirm such an impact of parental level of education in the development of unemployment scarring.

We found effects of an early unemployment episode on the development of unemployment scarring regardless of the status of substance-use behaviours. However, such effects on unemployment scarring appear to be higher amongst young people with a history of problematic substance-use behaviours. Prior evidence has demonstrated that problematic substance use may increase the risk of becoming and remaining unemployed, since it negatively affects productivity, work performance, work absences and other risk factors associated with unemployment (Ayllón et al., Chapter 9 this volume; Henkel, 2011).

A significant impact of mental distress on unemployment scarring is only found amongst those with low rather than high levels of mental distress. This could be related to characteristics of adolescents reporting a higher level of mental distress, who might have higher academic aspirations (Evensen et al., 2016), which may be a reason for experiencing a high level of mental distress but may not necessarily indicate a poor mental health status that diminishes the likelihood of participating and succeeding in education or the labour market. Alternatively, elevated levels of mental distress may be transitory - limited to the adolescent period - and thus have insignificant effects on future labour market outcomes.

\section{REFERENCES}

Abebe DS, Lien L, Torgersen L and Von Soest T (2012) Binge eating, purging and non-purging compensatory behaviours decrease from adolescence to adulthood: A population-based, longitudinal study. BMC Public Health 12(1): 32. DOI: 10.1186/1471-2458-12-32.

Barnea Z, Rahav G and Teichman M (1987) The reliability and consistency of self-reports on substance use in a longitudinal study. British Journal of Addiction 82(8): 891-8.

Becker GS (1964) Human Capital. A Theoretical and Empirical Analysis with Special Reference to Education. New York: Columbia University Press.

Bell DN and Blanchflower DG (2011) Young people and the Great Recession. Oxford Review of Economic Policy 27(2): 241-67.

Biewen M and Steffes S (2010) Unemployment persistence: Is there evidence for stigma effects? Economics Letters 106(3): 188-90. 
Caliendo M and Kopeinig S (2008) Some practical guidance for the implementation of propensity score matching. Journal of Economic Surveys 22(1): 31-72.

Caspi A, Wright BRE, Moffitt TE and Silva PA (1998) Early failure in the labor market: Childhood and adolescent predictors of unemployment in the transition to adulthood. American Sociological Review 63(3): 424-51.

Cochran WG and Rubin DB (1973) Controlling bias in observational studies: A review. Sankhyā: The Indian Journal of Statistics, Series A 35(4): 417-46.

Colder CR and Stice E (1998) A longitudinal study of the interactive effects of impulsivity and anger on adolescent problem behavior. Journal of Youth and Adolescence 27(3): 255-74.

Currie J (2009) Healthy, wealthy, and wise: Socioeconomic status, poor health in childhood, and human capital development. Journal of Economic Literature 47(1): 87-122. DOI: 10.1257/jel.47.1.87.

Daly M, Delaney L, Egan M and Baumeister RF (2015) Childhood self-control and unemployment throughout the life span: Evidence from two British cohort studies. Psychological Science 26(6): 709-23. DOI: 10.1177/0956797615569001.

Derogatis LR, Lipman RS, Rickels K, Uhlenhuth EH and Covi L (1974) The Hopkins Symptom Checklist (HSCL): A self-report symptom inventory. Behavioral Sciences 19(1): 1-15.

Elman C and O'Rand A (2004) The race is to the swift: Socioeconomic origins, adult education, and wage attainment. American Journal of Sociology 110(1): 123-60.

Evensen M, Lyngstad TH, Melkevik O and Mykletun A (2016). The role of internalizing and externalizing problems in adolescence for adult educational attainment: Evidence from sibling comparisons using data from the young HUNT study. European Sociological Review 32(5): 552-66. DOI: 10.1093/esr/jcw001.

Eysenck SB, Pearson PR, Easting G and Allsopp JF (1985) Age norms for impulsiveness, venturesomeness and empathy in adults. Personality and Individual Differences 6(5): 613-19.

Grasdal A (2001) Unemployment persistence among young Norwegian labour market entrants. Working Paper. Bergen: Department of Economics, University of Bergen.

Gregg P (2001) The impact of youth unemployment on adult unemployment in the NCDS. The Economic Journal 111(475): 626-53.

Gregg P and Tominey E (2005) The wage scar from male youth unemployment. Labour Economics 12(4): 487-509. DOI: 10.1016/j.labeco.2005.05.004.

Haas SA, Glymour MM and Berkman LF (2011) Childhood health and labor market inequality over the life course. Journal of Health and Social Behavior 52(3): 298-313.

Hämäläinen K (2003) Education and unemployment: State dependence in unemployment among young people in the 1990s. VATT Discussion Paper no. 312. Helsinki: VATT Institute for Economic Research.

Harter S (2012) Self-perception Profile for Adolescents. Manual and Questionnaire. Revised version. https://portfolio.du.edu/downloadItem/221931 (accessed 10 June 2018).

Healey A, Knapp M and Farrington DP (2004) Adult labour market implications of antisocial behaviour in childhood and adolescence: Findings from a UK longitudinal study. Applied Economics 36(2): 93-105.

Heckman JJ, Stixrud J and Urzua S (2006) The effects of cognitive and noncognitive abilities on labor market outcomes and social behavior. NBER Working Paper no. 12006. Cambridge, MA: National Bureau of Economic Research.

Helbling LA, Imdorf C, Ayllón S and Sacchi S (2016) Methodological challenges in 
the study of scarring effects of early job insecurity. NEGOTIATE Working Paper no. 6.1. https://negotiate-research.eu/files/2015/04/NEGOTIATE-working-paperno-D6.1-Methodological-challenges-in-the-study-1.pdf (accessed 10 June 2018).

Henkel D (2011) Unemployment and substance use: A review of the literature (1990-2010). Current Drug Abuse Reviews 4(1): 4-27.

Jensberg H, Mandal R and Solheim E (2012) Det kjønnsdelte arbeidsmarkedet 1990-2010. Kontinuitet eller endring? [The gender-segregated labour market 1990-2010. Continuity or change?] https://www.regjeringen.no/globalassets/up load/bld/sla/skjeieutvalget/september_2012/kjonnsdelte_arbeidsmarkedet.pdf (accessed 10 June 2018).

Johnson TP and Mott JA (2001) The reliability of self-reported age of onset of tobacco, alcohol and illicit drug use. Addiction 96(8): 1187-98.

Leuven E and Sianesi B (2011) Stata Documentation for the Psmatch2 Command. http://anciensite.pep-net.org/fileadmin/medias/pdf/Training_Material/statadoc. pdf (accessed 10 June 2018).

Luijkx R and Wolbers MH (2009) The effects of non-employment in early worklife on subsequent employment chances of individuals in the Netherlands. European Sociological Review 25(6): 647-60.

Masten AS, Desjardins CD, McCormick CM, Kuo SIC and Long JD (2010) The significance of childhood competence and problems for adult success in work: A developmental cascade analysis. Development and Psychopathology 22(3): 679-94. DOI: $10.1017 / \mathrm{s} 0954579410000362$.

Mooi-Reci I and Ganzeboom HB (2015) Unemployment scarring by gender: Human capital depreciation or stigmatization? Longitudinal evidence from the Netherlands, 1980-2000. Social Science Research 52: 642-58.

Nilsen ØA and Reiso KH (2011) Scarring effects of unemployment. CESifo Working Paper no. 3675. Munich: Ifo Institute.

Nordström Skans O (2004) Scarring effects of the first labour market experience: A sibling based analysis. IFAU Working Paper no. 14. Uppsala: Institute for Labour Market Policy Evaluation.

Parker G, Tupling H and Brown LB (1979) A parental bonding instrument. British Journal of Medical Psychology 52: 1-10.

Pedersen W, Mastekaasa A and Wichstrøm L (2001) Conduct problems and early cannabis initiation: A longitudinal study of gender differences. Addiction 96(3): 415-31.

Pedersen W and Wichstrøm L (1995) Patterns of delinquency in Norwegian adolescents. British Journal of Criminology 35(4): 543-62.

Pissarides CA (1992) Loss of skill during unemployment and the persistence of employment shocks. Quarterly Journal of Economics 107(4): 1371-91.

Raaum O and Røed K (2006) Do business cycle conditions at the time of labor market entry affect future employment prospects? Review of Economics and Statistics 88(2): 193-210.

Rosenbaum PR and Rubin DB (1983) The central role of the propensity score in observational studies for causal effects. Biometrika 70(1): 41-55.

Schmillen A and Umkehrer M (2013) The scars of youth: Effects of early-career unemployment on future unemployment experience. International Labour Review 156(3/4): 465-94.

Spence M (1973) Job market signaling. Quarterly Journal of Economics: 87(3): 355-74.

Strand BH, Dalgard OS, Tambs K and Rognerud M (2009) Measuring the mental 
health status of the Norwegian population: A comparison of the instruments SCL-25, SCL-10, SCL-5 and MHI-5 (SF-36). Nordic Journal of Psychiatry 57(2): 113-18.

Strand NP and Von Soest T (2008) Young in Norway - Longitudinal: Documentation of Design, Variables, and Scales. Oslo: NOVA.

Trzesniewski KH, Donnellan MB, Moffitt TE, Robins RW, Poulton R and Caspi A (2006) Low self-esteem during adolescence predicts poor health, criminal behavior, and limited economic prospects during adulthood. Developmental Psychology 42(2): 381-90.

Tumino A (2015) The scarring effect of unemployment from the early '90s to the Great Recession. ISER Working Paper no. 5. Essex, UK: Institute for Social and Economic Research, University of Essex.

Wichstrøm L (1995) Harter's self-perception profile for adolescents: Reliability, validity, and evaluation of the question format. Journal of Personality Assessment 65(1): $100-16$.

Wichstrøm L (2000) Psychological and behavioral factors unpredictive of disordered eating: A prospective study of the general adolescent population in Norway. International Journal of Eating Disorders 28(1): 33-42. 


\section{APPENDIX}

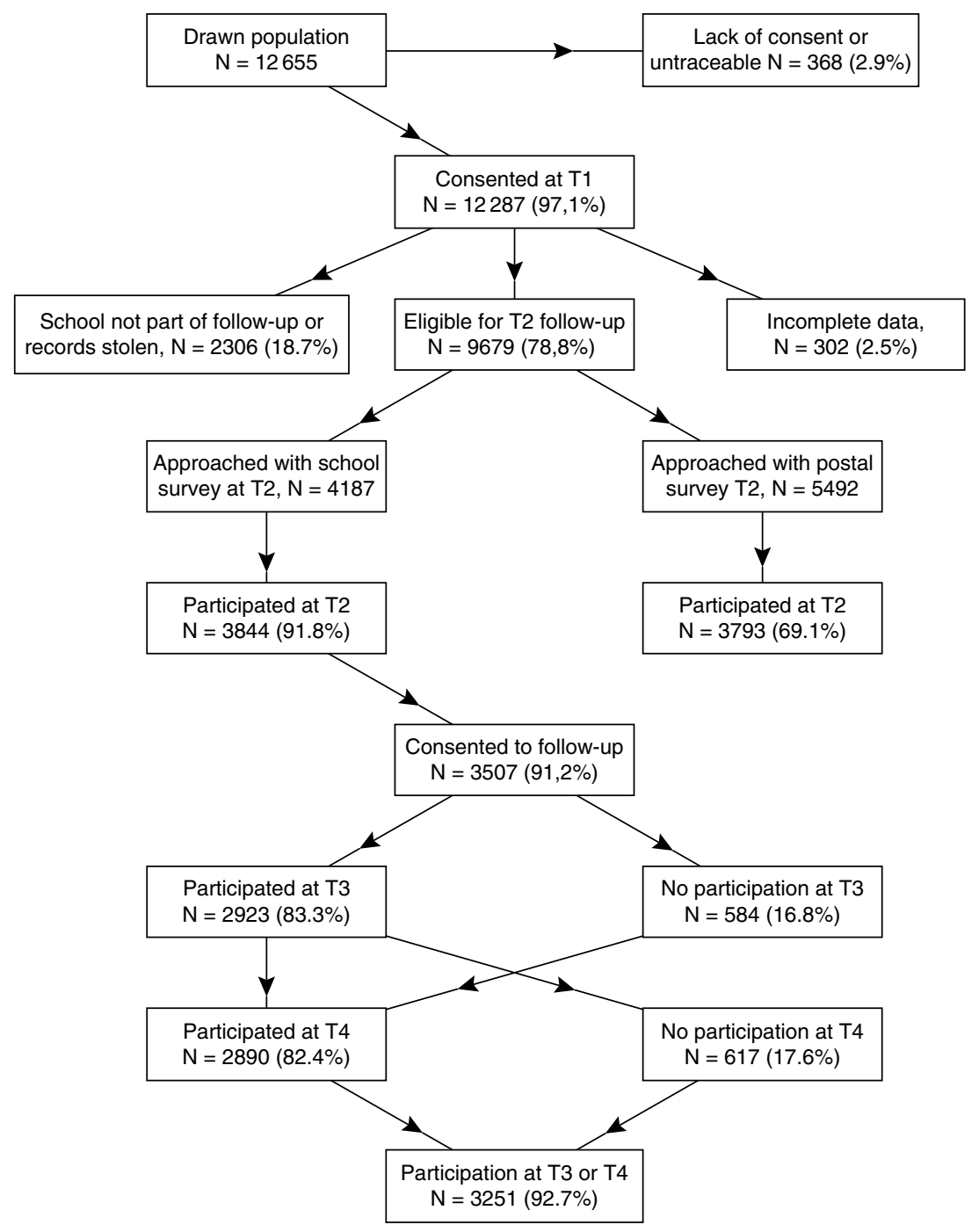

Source: Young in Norway study.

Figure 6A.1 Flow chart showing sampling design and participation rates in Young in Norway study 
Table 6A.1 Young in Norway longitudinal study - descriptive summary of study participants $(N=2123)$

\begin{tabular}{|c|c|c|}
\hline Variables & $\mathrm{N} / \mathrm{M}$ & $\% / \mathrm{sd}$ \\
\hline \multicolumn{3}{|l|}{ Age - M (sd) } \\
\hline T1 (1992) & 15.2 & 1.9 \\
\hline T2 (1994) & 16.6 & 1.9 \\
\hline T3 (1999) & 22.1 & 1.8 \\
\hline T4 (2005) & 28.6 & 1.9 \\
\hline \multicolumn{3}{|l|}{ Gender - N (\%) } \\
\hline Male & 949 & 44.7 \\
\hline Female & 1174 & 55.3 \\
\hline \multicolumn{3}{|l|}{ Level of education $-\mathrm{N}(\%)$} \\
\hline Junior/Secondary & 954 & 44.9 \\
\hline College/University & 1168 & 55 \\
\hline \multicolumn{3}{|l|}{ Parental level of education at age $16-\mathrm{N}(\%)$} \\
\hline Junior/Secondary & 909 & 43.1 \\
\hline College/University & 1201 & 56.9 \\
\hline \multicolumn{3}{|l|}{ Parental relationships $-\mathrm{M}(\mathrm{sd})$} \\
\hline Overprotective at $\mathrm{T} 1$ & 2.1 & 0.5 \\
\hline Overprotective at $\mathrm{T} 1$ & 2.0 & 0.5 \\
\hline Caring at $\mathrm{T} 1$ & 3.2 & 0.5 \\
\hline Caring at $\mathrm{T} 2$ & 3.1 & 0.5 \\
\hline More often alcohol intoxication at T1 - N (\%) & 213 & 10.9 \\
\hline More often alcohol intoxication at T2 - N (\%) & 370 & 17.7 \\
\hline Use of cannabis at $\mathrm{T} 1-\mathrm{N}(\%)$ & 58 & 2.9 \\
\hline Use of cannabis at $\mathrm{T} 2-\mathrm{N}(\%)$ & 114 & 5.5 \\
\hline Conduct problems at $\mathrm{T} 1-\mathrm{M}(\mathrm{sd})$ & 1.3 & 0.4 \\
\hline Conduct problems at $\mathrm{T} 2-\mathrm{M}(\mathrm{sd})$ & 1.4 & 0.4 \\
\hline Mental distress at $\mathrm{T} 1-\mathrm{M}(\mathrm{sd})$ & 1.5 & 0.4 \\
\hline Mental distress at T2 - M (sd) & 1.6 & 0.5 \\
\hline Scholastic competence at T1 - M (sd) & 2.8 & 0.5 \\
\hline Scholastic competence at T2 - M (sd) & 2.9 & 0.5 \\
\hline Self-esteem at T1 - M (sd) & 2.9 & 0.5 \\
\hline Self-esteem at T2 - M (sd) & 3.0 & 0.5 \\
\hline Impulsivity at $\mathrm{T} 3-\mathrm{M}$ (sd) & 2.5 & 0.4 \\
\hline
\end{tabular}

Notes: $\quad \mathrm{T} 1-\mathrm{T} 4$ represent survey time points; $\mathrm{N}=$ number; $\mathrm{M}=$ Mean; $\%=$ percentage; $\mathrm{sd}=$ standard deviation.

Source: Young in Norway longitudinal study. 
Table 6A.2 Average effect on treated (early unemployed) group for unemployment and wage scarring amongst females and males over time

\begin{tabular}{llcc}
\hline $\begin{array}{l}\text { Matching } \\
\text { methods }\end{array}$ & Caliper & \multicolumn{2}{c}{ Outcomes $-\mathrm{B}(\mathrm{SE})$} \\
\cline { 3 - 4 } & & $\begin{array}{c}\text { Unemployment } \\
\text { scarring }\end{array}$ & $\begin{array}{c}\text { Wage scarring } \\
\text { (income in 1000 NOK) }\end{array}$ \\
\hline Females & & & \\
Kernel & 0.01 & $0.095(0.031)^{* *}$ & $-41.584(9.918)^{* * *}$ \\
& 0.001 & $0.094(0.022)^{* *}$ & $-41.584(8.939)^{* * *}$ \\
Radius & 0.01 & $0.086(0.033)^{* *}$ & $-41.449(12.709)^{* *}$ \\
& 0.001 & $0.083(0.037)^{*}$ & $-42.519(14.823)^{*}$ \\
Males & & & \\
Kernel & 0.01 & $0.061(0.028)^{*}$ & $-51.409(47.093)$ \\
& 0.001 & $0.061(0.033)$ & $-51.409(48.572)$ \\
Radius & 0.01 & $0.058(0.025)^{*}$ & $-57.100(41.782)$ \\
& 0.001 & $0.055(0.029)$ & $-48.516(46.591)$ \\
\hline
\end{tabular}

Notes: $\quad \mathrm{B}=$ observed regression coefficients with bootstrap standard errors in parentheses; *** $\mathrm{p}<0.001,{ }^{* *} \mathrm{p}<0.01,{ }^{*} \mathrm{p}<0.05$.

Source: Young in Norway longitudinal study. 
Table 6A.3 Average effect on treated (early unemployed) group for unemployment and wage scarring amongst those with low and high levels of education over time

\begin{tabular}{lccc}
\hline $\begin{array}{l}\text { Matching } \\
\text { methods }\end{array}$ & Caliper & \multicolumn{2}{c}{ Outcomes $-\mathrm{B}(\mathrm{SE})$} \\
\cline { 3 - 4 } & & $\begin{array}{c}\text { Unemployment } \\
\text { scarring }\end{array}$ & $\begin{array}{c}\text { Wage scarring } \\
\text { (income in 1000 NOK) }\end{array}$ \\
\hline \multicolumn{2}{l}{ Low level of education } & & \\
Kernel & 0.01 & $0.111(0.029)^{* * *}$ & $-55.694(17.830)^{* *}$ \\
& 0.001 & $0.101(0.043)^{*}$ & $-55.694(21.361)^{* *}$ \\
Radius & 0.01 & $0.095(0.037)^{* *}$ & $-54.631(22.810)^{*}$ \\
& 0.001 & $0.107(0.046)^{*}$ & $-36.615(33.554)$ \\
High level of education & & \\
Kernel & 0.01 & $0.059(0.023)^{*}$ & $-34.0255(26.990)$ \\
& 0.001 & $0.059(0.033)$ & $-34.025(26.060)$ \\
Radius & 0.01 & $0.059(0.030)$ & $-40.593(30.704)$ \\
& 0.001 & $0.039(0.032)$ & $-46.397(37.730)$ \\
\hline
\end{tabular}

Notes: $\quad \mathrm{B}=$ observed regression coefficients with bootstrap standard errors in parentheses; *** $\mathrm{p}<0.001,{ }^{* *} \mathrm{p}<0.01,{ }^{*} \mathrm{p}<0.05$.

Source: Young in Norway longitudinal study. 
Table 6A.4 Average effect on treated (early unemployed) group for unemployment and wage scarring amongst those with low and high levels of parental education over time

\begin{tabular}{|c|c|c|c|}
\hline \multirow{2}{*}{$\begin{array}{l}\text { Matching } \\
\text { methods }\end{array}$} & \multirow[t]{2}{*}{ Caliper } & \multicolumn{2}{|c|}{ Outcomes - B(SE) } \\
\hline & & $\begin{array}{l}\text { Unemployment } \\
\text { scarring }\end{array}$ & $\begin{array}{c}\text { Wage scarring } \\
\text { (income in } 1000 \mathrm{NOK} \text { ) }\end{array}$ \\
\hline \multicolumn{4}{|c|}{ Low levels of parental education } \\
\hline Kernel & $\begin{array}{l}0.01 \\
0.001\end{array}$ & $\begin{array}{l}0.083(0.032)^{*} \\
0.083(0.031)^{* *}\end{array}$ & $\begin{array}{l}-71.072(32.984)^{*} \\
-71.072(26.141)^{* *}\end{array}$ \\
\hline Radius & $\begin{array}{l}0.01 \\
0.001\end{array}$ & $\begin{array}{l}0.081(0.034)^{*} \\
0.091(0.045)^{*}\end{array}$ & $\begin{array}{l}-69.798(48.680) \\
-55.378(34.236)\end{array}$ \\
\hline \multicolumn{4}{|c|}{ High levels of parental education } \\
\hline Kernel & $\begin{array}{l}0.01 \\
0.001\end{array}$ & $\begin{array}{l}0.083(0.031)^{*} \\
0.083(0.034)^{*}\end{array}$ & $\begin{array}{l}-29.324(26.709) \\
-29.324(17.946)\end{array}$ \\
\hline Radius & $\begin{array}{l}0.01 \\
0.001\end{array}$ & $\begin{array}{l}0.082(0.030)^{* *} \\
0.087(0.029)^{* *}\end{array}$ & $\begin{array}{l}-30.326(33.629) \\
-43.719(28.211)\end{array}$ \\
\hline
\end{tabular}

Notes: $\quad \mathrm{B}=$ observed regression coefficients with bootstrap standard errors in parentheses; *** $\mathrm{p}<0.001,{ }^{* *} \mathrm{p}<0.01,{ }^{*} \mathrm{p}<0.05$.

Source: Young in Norway longitudinal study. 
Table 6A.5 Average effect on treated (early unemployed) group for unemployment and wage scarring amongst those with low and high levels of mental distress over time

\begin{tabular}{lccc}
\hline $\begin{array}{l}\text { Matching } \\
\text { methods }\end{array}$ & Caliper & \multicolumn{2}{c}{ Outcomes $-\mathrm{B}(\mathrm{SE})$} \\
\cline { 3 - 4 } & & $\begin{array}{c}\text { Unemployment } \\
\text { scarring }\end{array}$ & $\begin{array}{c}\text { Wage scarring } \\
\text { (income in 1000 NOK) }\end{array}$ \\
\hline Low levels of mental distress & & \\
Kernel & 0.01 & $0.081(0.028)^{* *}$ & $-34.215(18.286)$ \\
& 0.001 & $0.082(0.025)^{* *}$ & $-34.215(20.194)$ \\
Radius & 0.01 & $0.082(0.023)^{* * *}$ & $-34.690(17.512)^{*}$ \\
& 0.001 & $0.063(0.032)^{*}$ & $-37.345(24.854)$ \\
High levels of mental distress & & \\
Kernel & 0.01 & $0.089(0.047)$ & $-87.050(60.537)$ \\
& 0.001 & $0.089(0.055)$ & $-87.050(49.791)$ \\
Radius & 0.01 & $0.104(0.074)$ & $-73.154(76.847)$ \\
& 0.001 & $0.095(0.075)$ & $-52.976(53.101)$ \\
\hline
\end{tabular}

Notes: $\quad \mathrm{B}=$ observed regression coefficients with bootstrap standard errors in parentheses; *** $\mathrm{p}<0.001,{ }^{* *} \mathrm{p}<0.01,{ }^{*} \mathrm{p}<0.05$.

Source: Young in Norway longitudinal study. 
Table 6A.6 Average effect on treated (early unemployed) group for unemployment and wage scarring amongst those with and without problematic substance-use behaviours over time

\begin{tabular}{|c|c|c|c|}
\hline \multirow{2}{*}{$\begin{array}{l}\text { Matching } \\
\text { methods }\end{array}$} & \multirow[t]{2}{*}{ Caliper } & \multicolumn{2}{|c|}{ Outcomes - B(SE) } \\
\hline & & $\begin{array}{l}\text { Unemployment } \\
\text { scarring }\end{array}$ & $\begin{array}{c}\text { Wage scarring } \\
\text { (income in } 1000 \text { NOK) }\end{array}$ \\
\hline \multicolumn{4}{|c|}{ Without problematic substance use } \\
\hline Kernel & $\begin{array}{l}0.01 \\
0.001\end{array}$ & $\begin{array}{l}0.068(0.028)^{*} \\
0.068(0.028)^{*}\end{array}$ & $\begin{array}{r}-51.963(13.753)^{* * *} \\
51.963(14.327)^{* * *}\end{array}$ \\
\hline Radius & $\begin{array}{l}0.01 \\
0.001\end{array}$ & $\begin{array}{l}0.069(0.023)^{*} \\
0.048(0.031)\end{array}$ & $\begin{array}{l}-48.063(17.822)^{* *} \\
-40.789(23.416)\end{array}$ \\
\hline \multicolumn{4}{|c|}{ With problematic substance use } \\
\hline Kernel & $\begin{array}{l}0.01 \\
0.001\end{array}$ & $\begin{array}{l}0.154(0.060)^{*} \\
0.153(0.049)^{* *}\end{array}$ & $\begin{array}{l}-20.666(46.142) \\
-20.666(40.845)\end{array}$ \\
\hline Radius & $\begin{array}{l}0.01 \\
0.001\end{array}$ & $\begin{array}{l}0.154(0.058)^{* *} \\
0.158(0.071)^{*}\end{array}$ & $\begin{array}{l}-16.795(57.362) \\
-44.202(70.510)\end{array}$ \\
\hline
\end{tabular}

Notes: $\quad \mathrm{B}=$ observed regression coefficients with bootstrap standard errors in parentheses; *** $\mathrm{p}<0.001,{ }^{* *} \mathrm{p}<0.01,{ }^{*} \mathrm{p}<0.05$.

Source: Young in Norway longitudinal study. 